\title{
Level of Knowledge, Attitude and Behaviour Against Alcoholic Drinks in Abiansemal Village, Bali
}

\author{
I Wayan Darwata ${ }^{1}$, Igam Aditya Prasada Mahayana ${ }^{1}$, DAP Ratna Juwita ${ }^{\text {1* }}$ \\ ${ }^{1}$ Faculty of Medicine and Health Science, Warmadewa University, Indonesia \\ *ratnajwt_unwar@yahoo.com
}

\begin{abstract}
Alcoholic drinks or beverages contains of fermented/dystalated carbohydrates called ethanol $(\mathrm{C} 2 \mathrm{H} 5 \mathrm{OH})$. Drinking alcohol plays an important social roles in many cultures and are legal in most parts of the world. Alcohol is a depressant, which in low doses causes reduce anxiety, improves socialbility and euphoria. In higher doses cause drunkennes, unconsciousness and death. Long-term use can lead to alcohol abuse, cancer, cardiovascular dissease, neuropsyciatric dissease, gastrointestinal problems, congenital anomalies and alcoholism. Alcohol is the most recreational drugs in the world with about $38,3 \%$ people above 15 yo being current drinkers. In Indonesia, 4,6\% of above 15 yo people being current drinkers. In Indonesia, alcohol consumption and trade is restricted by high taxation and limited bans, eventhough $28,4 \%$ of alcohol drinks are illegal production/homade that out of government controls. In 2015, the Indonesian government banned the sale of alcohol from the small shop with the exception of Bali Province as the most local and international tourism destination. This research takes place in Abiansemal Village, Bali with quantitative descriptive using cross-sectional approach. The number of samples were 96 obtained by the formula using multistage random sampling technique. The results indicate that the level of knowledge and attitude is mostly good $(67,7 \%$ and $63,5 \%$ ), while the level of behaviour is $56,1 \%$. An active roles of health workers and government are needed to prevent the increase of long-term drinkers population so that decrease the impact of alcohol related dissease in population.
\end{abstract}

Keyword : Knowledge, Attitude and Behaviour, Alcoholic.

\section{Introduction}

Alcoholic beverages is a drink that contain ethanol $(\mathrm{C} 2 \mathrm{H} 5 \mathrm{OH})$, a type of alcohol produced of fermented or distalated fruits, grains or other sources of sugar. Alcoholic drinks are typically divided in to three class: beers, spirits, and wines which contains of 3-50\% alcohol content. A fermented alcoholic drinks such as beer is made from barley of several grains and flavore with hops, while wine is made from grapes or other fruits. A destylated alcoholic drinks such as spirits, named as whiskey or vodka are made from grain, fruits, and vegetables [1].

Alcoholic drinks is a depressant, which in low doses causes reduce anxiety, improves socialbility and euphoria. In higher doses cause drunkennes, unconsciousness and death. Long-term use can lead to alcohol abuse, cancer, cardiovascular dissease, neuropsyciatric dissease, gastrointestinal problems, congenital anomalies and alcoholism [1,2].

Drinking alcohol plays an important social roles in many cultures and are legal in most parts of the world and have been a part of social life. Drinking is associated with displays of masculinity or male camaraderie. WHO survey in 2004 in Southeast Asia reported that the total consumption of alcohol is 3,1litres of absolute alcohol and 13,7 litres consumption per 
drinker of $35 \%$ male and $9 \%$ female current drinkers. Some study reported that men are more than twice as likely as women to have a heavy episodic drinking (at least 60 gram of ethanol per day). In 2012, WHO reported $38,3 \%$ of above 15 yo populations consume 6,2 litres alcoholic drinks in a year in which $28,4 \%$ of alcohol drinks are illegal production/hommade that out of government controls. Alcohol is the most recreational drugs in the world with about $30,2 \%$ between $15-19$ yo and $52,9 \%$ between 20 -24yo males and also 3,5\% between $15-19$ yo and $7,1 \%$ being current drinkers $[2,3]$.

In Indonesia, alcohol consumption and trade is restricted by high taxation and limited bans. In 2015, the Indonesian government banned the sale of alcohol from the small shop with the exception of Bali Province as the most local and international tourism destination. The high prices of alcoholic drinks in Bali has led to cases of illegal alcohol. Locals turn to illegal bootlegged alcohol for a cheaper drinks, known as solved alcohol and account of more than $80 \%$ alcohol consumed. Abiansemal village is located in in Bali province which has many distribution of alcoholic illegal drinks even in a small shops. It contributed for the increase drinkers in young age population. We interested in identifyng level of knowledge, attitude, and behaviour of population against alcoholic drinks in order to contribute the governments need to provide the regulation to prevent the harmfull side effect of consuming alcohol $[4,5]$.

\section{Method}

This study takes place in eight district of Abiansemal Village, Bali Province, Indonesia in August-Desember 2017 using quantitative descriptive design with cross-sectional approach. The target population is all the population ( 7.529 person) in eight district. The number of samples were 96 obtained by the formula using multistage random sampling technique. Data was collected by interview based on structured questionnaire and the measurement of knowledge, attitude, and behaviour against alcoholic drinks were delivered by well-trained officers. The structured questionnaire contains of ten item question of knowledge, eight item question of attitude, and 14 item question of behaviour. The clasification are: good $(>75 \%)$, medium $(56-74 \%)$, and low $(<55 \%)$. Drinking level defined into three categories: low alcohol use $(0,2 \mathrm{~g}-5,9 \mathrm{~g})$, moderate alcohol use $(6,0 \mathrm{~g}-27,9 \mathrm{~g})$ and heavy alcohol use $(>28 \mathrm{~g})$ [4].

\section{Results And Discussion}

Characteristics of sample based on each variable are presented on table below:

Table 1. Characteristics of samples

\begin{tabular}{lcc}
\hline \multicolumn{1}{c}{ Characteristics } & Frequency & $\%$ \\
\hline Age groups & & \\
$-\leq 44$ yo & 48 & 50.0 \\
$-45-49$ yo & 41 & 42.7 \\
$\quad-\quad \geq 60$ yo & 7 & 7.3 \\
Education & & \\
$\quad$ School & 19 & \\
$\quad-\quad$ Elementary & & 19.8 \\
$\quad$ School & 61 & 63,5 \\
$\quad-\quad$ Junior \& Senior High & &
\end{tabular}




\begin{tabular}{lcc}
\hline Characteristics & Frequency & $\%$ \\
\hline School & & 16.7 \\
\hline - University & 16 & \\
Occupation & & 30.2 \\
- Trader & 29 & 28.1 \\
- Farmer & 27 & 37.5 \\
- Employer & 36 & 4.2 \\
- Others & 4 & 100 \\
$\quad$ Total number & 96 & \\
\hline
\end{tabular}

As shown by the Table 1, the highest proportion was observed in age group of $\leq 44$ yo $(50.0 \%)$, followed by $45-49$ yo $(42.7 \%)$, and $\geq 60$ yo (7,3\%). Most of the participants junior and high school graduated $(63.5 \%), 19.8 \%$ is elementary school and $16.7 \%$ held university. The majority of subjects' occupations was employer (37.5\%), 30.2\% were trader, followed by farmer $(28.1 \%)$.

Table 2. Level of Alcoholic Drinks Consumption

\begin{tabular}{lcc}
\hline \multicolumn{1}{c}{ Characteristics } & Frequency & $\%$ \\
\hline No alcohol use & 14 & 14.6 \\
Low alcohol use & 18 & 18.8 \\
Moderate alcohol use & 25 & 26.0 \\
Heavy alcohol use & 39 & 40.6 \\
Total number & 96 & 100 \\
\hline
\end{tabular}

As shown by the Table 2, the highest proportion was observed in heavy alcohol use (40.6\%), moderate alcohol use (26.0\%), low alcohol use (18.8\%), and no alcohol use (14.6\%).

Table 3. Sources of Alcohol Information

\begin{tabular}{lcc}
\hline \multicolumn{1}{c}{ Sources } & $\mathrm{N}$ & \% \\
\hline Health workers (docter, nurse) & 14 & 14.6 \\
Mass media & 85 & 88.5 \\
Electronic media (radio,tv) & 86 & 90.6 \\
Internet (website, social media) & 39 & 40.6 \\
Total number & 96 & 100 \\
\hline
\end{tabular}

As shown by the Table 3, among the finding, electronic media (tv and radio) is the primary sources of information (90.6\%), mass media is secondary source $(88.5 \%)$, internet $(52.15 \%)$ and health workers is lack (only $37.5 \%$ ).

Based on age groups, occupational groups, educational level, and level of alcoholic drinks, the highest proportion of good level of alcoholic knowledge were in age group $\leq 44$ yo, traders, universities graduated, and moderate drinks. Otherwise the highest proportion of low level of alcoholic knowledge were in age group 45-49yo, farmers, elementary school graduated, and heavy drinks.

Based on age groups, occupational groups, educational level, and level of alcoholic drinks; the highest proportion of good level of attitude were observed in age group $\leq 44$ yo, employments, universities graduated and mild level of alcoholic drinks. Otherwise age group $\geq 60$ yo, farmers, elementary school, and heavy drinks has the greatest portion of knowledge low level of attitude. 
Alcoholic behavioural item questionnaire found that the most favorite alcoholic baverages is beer, and only few respondents drink wine. Based on age groups, occupational groups, educational level, and level of alcoholic drinks; the highest proportion of good level of behaviour were observed in age group $\geq 60$ yo, traders, mild alcholic use and elementary school graduates. Otherwise age group 45-49yo, farmers, heavy alcoholic use and universities graduated has the greatest portion of low level behavior

Table 4. Level of Knowledge and Attitude Distribution

\begin{tabular}{lcccc}
\hline \multirow{2}{*}{ Level of Knowledge } & \multirow{2}{*}{$\mathrm{N}$} & Good & Attitude $(\%)$ & Moderate \\
\cline { 3 - 5 } & & $45(62.2)$ & $18(27.7)$ & $2(3.1)$ \\
Good & 65 & $15(55.6)$ & $10(37.0)$ & $2(7.4)$ \\
Moderate & 27 & $1(25.0)$ & $3(75.0)$ & $0(0.0)$ \\
Low & 4 & $61(63.5)$ & $31(32.3)$ & $4(4.2)$ \\
Total number & 96 & &
\end{tabular}

As shown by the Table 4, the good level of knowledge has a good level of attitude $(62.2 \%)$, otherwise the low level of knowledge has a highest portion of moderate attitude level (75.0\%).

This study identified that the amount of alcoholic drinkers in Abiansemal Village was relatively high whereas active drinkers were found in $85.4 \%$ population and $14.6 \%$ do not drink alcoholic drinks. The highest proportion of an active drinkers is a heavy use of alcohol $(40.6 \%)$. This data was coherent with the study in Sulawesi Island, Indonesia 2015 stating that most of population in those village is a heavy use of alcoholic drinks. Monteiro and Panggabean study in 2015 also reported that the total number of alcoholic drinks consumption is as high as the alcohol production itself, more ever study of Aritonang 2012 reported that in low economic status of Indonesian, the number of alcoholic consumption is quite high based on the local alcoholic drinks production which is in lower price[6,7,8].

The lack sources of alcohol information is came from the health workers $(14.6 \%)$, eventhough that health workers has main responsibility for giving health information. Its similar with the Panggabean study in 2015 stated that the society get lack of alcohol side effect information from the health workers. Account for $67.7 \%$ the level of knowledge about alcoholic drinks is good, this similar with Manandhar et al study in Nepal stating that most population has a good level of knowledge about alcoholic drinks. Over all, the level of attitude of peoples about alcohol was good (63.5\%), it was similar with the study in Manado, Indonesia 2015 stating that most of peoples have a good attitude in alcholic issues. Data of behavioral description divided the population between actively alcohol use (85.4\%) and not use alcoholic drinks (14.6\%). Most of active drinkers responden was found has a good behaviour of alcoholic use $(56.1 \%)$. It is relatively different in other site of study. The study in East Java and Makasar, Indonesia found that most of the population have low level of behaviour state $[9,10,11]$.

Based on this study, the highest proportion of respondents who has a good level of knowledge coherent with the attitude item matters and it was similar with the study in in Makasar, 2013. Teoritically, level of knowledge plays an importan role build the character of attitude and behavioural changed for some information, especially about the alcohol consumption and side abuse effect [12.13].

\section{Conclusions}

The responden of Abiansemal Village mostly knowledgeable about alcohol, the harmfull effects on health and society. The possessed a positive attitude and positive behavioural change is needed by government and healthworkers towards anti-substance use campaign against unhealty behavioural changes, for increasing the level of good behavioural changes. Effective school-based policies, practise and parenteral education accompanied with mass media and electronic information is needed to help society curbing this pathognomonic issues. 


\section{References}

[1] Cremonte M, Cherphitel C. 2014. Alcohol Intake and Risk Injury. Medicina (B Aires) 74(4): 287-292.

[2] World Health Organization. 2014. Global Status Report on Alcohol and Health. Geneva.

[3] Health Department of Republic Indonesia. 2013. Demography and Health Survey 2012.

[4] Bender, DA. 2006. Dictionary Of Nutrition And Food Technology. Ed ke-8. England: Woodhead Publishing Ltd.

[5] Presidential Decree of Republic Indonesia Number 74, 2013. Surveillance and Control of Alcoholic Beverages. Jakarta.

[6] World Health Organization. 2018. Global Status Report on Alcohol and Health 2018. Geneva.

[7] Monteiro, Maristela; Shield Kevin; Rehm, Jurgen. 2015. Alcohol Consumption: An Overview of International Trends. In Reference Module of Biomedical Science.

[8] Penggabean, SM. 2015. Consumption Tuak Analysis of Tuak's Drinkers in Lumban Village, Jakarta: Faculty of Medicine of Islam Negeri Syarif Hidayahtullah Siagian Jae University, District of Barita, North Tapanuli 2015.

[9] Aritonang, Uci LM, 2012. Description of Tuak Consumption and Health Status of Man adolescence in Suka Maju Village, Pahae Jae Distric of North Tapanuli. North Sumatera: Faculty of Medicine North Sumatera University.Budiman, R., Polii, B., Engkeng, S. 2017.

[10] Manandhar, N., Shrestha, M., Joshi, S. 2017. Prevalence of Alcohol Consumption and Knowledge About Alcohol at Bhimtar, Sindhupalchowk. Department of Community Medicine, Kathmandu Medical College, Sinamangal, Kathmandu, Nepal. Nepal Med Assoc 56(207):2937.

[11] Population Habits of Alcoholic Beverages and Impacts of Health Issues in Tuminting District, Manado. Faculty of Medicine, Sam Ratulangi University. E-journal medkes vol 9, no 3.

[12] Sudarman. 2017. The Relationship of Knowledge Level with Alcoholic Drink Behaviour. Faculty of Medicine Islam Negeri Alauddin University.

[13] Anggraeny, R., Wahiddudin, Rismayanti. 2013. The Risk factors of Physical Activities, Smooking and Alcohol Consumption With Hypertension in Elderly Pattingalloang Town, Makassar. Faculty of Medicine Hasanuddin University.

[14] Sulistyowati D. 2012. The Relationship of Knowledge and Teenager Attitude of the Alcholic Beverages with Alcoholic Consumption Behaviour in Klumprit Village, Sukoharjo. Surakarta: Faculty of Medicine, Muhammadiyah University. 